\title{
A Model for TSUnami FLow INversion from Deposits (TSUFLIND)
}

\author{
Hui Tang ${ }^{\mathrm{a}, *}$, Robert Weiss ${ }^{\mathrm{a}}$ \\ ${ }^{a}$ Department of Geoscience, Virginia Polytechnic State University, United States
}

Abstract

Modern tsunami deposits are employed to estimate the overland flow characteristics of tsunamis. With the help of the overland-flow characteristics, the characteristics of the causative tsunami wave can be estimated. The understanding of tsunami deposits has tremendously improved over the last decades. There are three prominent inversion models: (a) Moore's advection model [Moore et al. 2007], (b) Soulsby's model [Soulsby et al. 2007], and (c) TsuSedMod [Jaffe and Gelfenbuam 2007]. TSUFLIND incorporates all three models and adds new modules to better simulate tsunami deposit formation and calculate flow condition. TSUFLIND takes grain-size distribution, thickness, water depth and topography information as inputs. TSUFLIND computes sediment concentration, grain-size distribution of sediment source and initial flow condition to match the sediment thickness and grain size distribution from field observation. Furthermore, TSUFLIND estimates the flow speed, Froude number and representative wave amplitude. The model is tested by using field data collected at Ranganathapuram, India after the 2004 India Ocean tsunami. TSUFLIND reproduces the field measurement grain-

\footnotetext{
${ }^{*}$ Corresponding author

Email address: tanghui@vt.edu (Hui Tang)

Preprint submitted to Marine Geology

October 14, 2015
}

(C) 2015. This manuscript version is made available under the Elsevier user license http://www.elsevier.com/open-access/userlicense/1.0/ 
size distribution with less than $5 \%$ error. Tsunami speed in this test case is about $4.7 \mathrm{~ms}^{-1}$ at 150 meters inland and decreases to $3.3 \mathrm{~ms}^{-1} 350$ meters inland from the shoreline. The estimated wave amplitude of the largest wave for this test case is about 5 to 7 meters.

Keywords: Tsunami, Tsunami sediment, Sediment transport, Flow depth, Flow speed, Inversion model

1

2

\section{Introduction}

The tsunami events that occurred over the last decades have caused an increase in public awareness and resulted in more research on the tsunami wave. Tsunami deposits play an important role not only in tsunami hazard assessments, but also in interpreting tsunami hydraulics [Hutchinson et al. 1997; Moore et al. 2007; Jaffe and Gelfenbuam 2007]. To draw any useful quantitative conclusions from tsunami deposits, the information from deposits about the causative tsunami needs to be extracted either by comparing parameters from the deposits with results from forward models [see Bourgeois et al. 1988; Martin et al. 2008] or by inversion models directly [see Nott 1997; Noormets et al. 2004; Jaffe and Gelfenbuam 2007; Moore et al. 2007; Soulsby et al. 2007; Smith et al. 2007; Benner et al. 2010; Nandasena and Tanaka 2013].

Tsunami inversion models attempt to link the basic information of the tsunami deposits with the overland flow characteristics. There are three prominent inversion models: Moore's advection model [Moore et al. 2007], Soulsby's model [Soulsby et al. 2007] and TsuSedMod model [Jaffe and Gelfenbuam 2007]. It should be noted that all these models are based on different basic assumptions and employ different information from the deposits. For 
example, Moore's advection model estimates tsunami flow magnitude by determining the combination of flow velocity and depth to move the largest grain from the sediment source to the deposition area [Moore et al. 2007]. In this paper, we present a joint inversion framework (TSUFLIND), which combines these three models. TSUFLIND not only couples all these three inversion models, but also contains a new method to calculate deposit characteristics [Tang and Weiss 2014]. It also uses the calculated flow depth and water volume from Soulsby's model to estimate a representative offshore tsunami wave amplitude.

\section{Theoretical Background}

\subsection{Inversion Models Employed}

As mentioned above, there are three prominent tsunami deposition inversion models that will be used: Moore's advection model, Soulsby's model and TsuSedMod model.

[Figure 1 about here.]

(a) Moore's model: Moore et al. [2007] assumes that some grains in the sediment source do not move because the tsunami flow is not strong enough. Furthermore, it is assumed that most grains are transported in suspension. Based on these assumptions, the shear velocity is determined for the largest grain in the tsunami deposits. The law of the wall can be employed to find the shear stress, which is necessary to move the largest grain to get a flow velocity $U$. The following equation is used to determine deposition. 


$$
\frac{h}{w_{s}}=t=\frac{l}{U}
$$

41

$$
\zeta_{0}^{(i)}=\frac{C_{0}^{(i)} w_{s}^{(i)} T_{d}}{(1-p) \rho_{s}\left(1+\alpha^{(i)}\right)}\left(1+\alpha^{(i)} \gamma\right)
$$

57 where $\alpha^{(i)}=\frac{w_{s}^{(i)} T_{d}}{H_{0}}, w_{s}^{(i)}$ denotes the settling velocity for grain size $i, T_{d}=(1-$ $\left.{ }_{58} \gamma\right) T$ is the deposition time. $C_{0}^{(i)}$ is the depth averaged sediment concentration 
59

71 For the grain size $i$, the sediment thickness $\Delta \eta^{(i)}$ is given by:

$$
\Delta \eta^{(i)}=\frac{1}{(1-p)} \int_{0}^{H(x)} C^{(i)}(z) d z
$$

72

$$
\zeta^{(i)}(x)=\left\{\begin{array}{rl}
\zeta_{0}^{(i)}\left(1-\frac{x}{R_{s}^{(i)}}\right) & x<R_{s}^{(i)} \\
0 & x \geq R_{s}^{(i)}
\end{array}\right.
$$

where $R_{s}^{(i)}$ is the distance between sediment extent and the shoreline for grain size $i$ [Soulsby et al. 2007].

(c) TsuSedMod:. Jaffe and Gelfenbuam [2007] developed an inversion model based on sediment deposited from suspension. There are several basic assumptions in TsuSedMod: (1) sediment is transported in suspension and deposited when steady and uniform tsunami flow slows down; (2) suspended sediment concentration is distributed in an equilibrium profile; (3) there is no erosion caused by return flow. The model iteratively adjusts the sediment source and the shear velocity to match the sediment grain-size distributions and thickness of suspension-grading sediment layers [Jaffe et al. 2011, 2012].$$
\text { For the gian size } i \text {, the selinent thickness } \Delta,(i) \text { is given by: }
$$

where $C^{(i)}(z)$ is the sediment concentration profile of grain size $i$. After determining the shear velocity, the flow speed profile is calculated by :

$$
U(z)=\int_{z_{0}}^{z} \frac{u_{*}^{2}}{K(z)} d z
$$

74 where $z_{o}$ is the bottom roughness from MacWilliams [2004] and $K(z)$ is the eddy viscosity profile from Gelfenbaum and Smith [1986]. 
The TsuSedMod model has been applied to four modern tsunami [Jaffe and Gelfenbuam 2007; Spiske et al. 2010; Jaffe et al. 2011, 2012] and two paleotsunami [Witter et al. 2012; Spiske et al. 2013b]. For the 2009 tsunami near Satitoa, Samoa, the flow speed estimated from TsuSedMod at three locations (100, 170 and 240 meters inland) were 3.6 to $3.8 \mathrm{~ms}^{-1}$ (bottom layer/earlier wave) and 4.1 to $4.4 \mathrm{~ms}^{-1}$ (top layer/later wave). These results are consistent with the 3 to $8 \mathrm{~ms}^{-1}$ flow speed from the boulder transport inverse model [Jaffe et al. 2011]. For more details about these three models, we refer to Jaffe and Gelfenbuam [2007], Moore et al. [2007], Soulsby et al. [2007] and Sugawara et al. [2014]

\subsection{Sedimentation model}

The method used to calculate the sediment concentration of the sediment source in TSUFLIND is similar to the one presented in Madsen et al. [1993]. The grain-size distribution of the sediment source is characterized by $D_{50}$, the largest grain and the smallest grain size.

When the entire tsunami deposit at a given location is considered, resuspension sediment flux can be neglected and Soulsby's model is applied. However, if the individual layer in the tsunami deposit is considered, intense turbulent mixing cannot be ignored. Therefore resuspension has to be taken into account. The generation of each individual portion of the tsunami sediment based on flow condition is the fundamental part to reconstruct tsunami deposits. For the entire deposit, the basic process is to calculate sediment thickness $\zeta^{(i)}(x)$ for each grain size at each point along the slope by using Eq (3) and (4) from Soulsby's model. We assume that the depth averaged sediment concentration $C_{0}$ in Eq (3) is the reference sediment concentration 
$C_{r}$ here. The reference concentration is calculated for a given flow condition with Madsen et al. [1993]:

$$
C_{r}^{(i)}=\frac{\beta_{0}(1-p) f^{(i)} S^{(i)}}{1+\beta_{0} S^{(i)}}
$$

where $\beta_{0}$ is the resuspension coefficient, $f^{(i)}$ is a fraction of the sediment of grain size $i . S^{(i)}$ is the normalized excess shear stress given by

$$
S^{(i)}=\left\{\begin{aligned}
\frac{\tau_{b}-\tau_{c r}^{(i)}}{\tau_{c r}^{(i)}} & \tau_{b}>\tau_{c r}^{(i)} \\
0 & \tau_{b} \leq \tau_{c r}^{(i)}
\end{aligned}\right.
$$

where $\tau_{b}$ is the bed shear stress and $\tau_{c r}^{(i)}$ is the critical shear stress of the initial sediment movement for grain size $i$ [Madsen et al. 1993].

For a given location $x$, the grain-size distribution for the entire tsunami deposit is given by:

$$
f^{(i)}=\frac{\zeta^{(i)}(x)}{\sum_{i=0}^{N} \zeta^{(i)}(x)} ; i=1,2,3, \ldots, N
$$

where $f^{(i)}$ is the percentage of grain size $i$ in the entire sediment, $\zeta^{(i)}(x)$ is sediment thickness of grain size $i$ and $\sum_{i=0}^{N} \zeta^{(i)}(x)$ is total deposit thickness for all grain sizes. $N$ is the number of grain size classes.

The tsunami deposit characteristics are reconstructed by matching sediment thickness and grain-size distribution with field data. In order to reconstruct deposit details, the sediment concentration cannot be depth averaged and is described as a Rouse-type suspended sediment concentration profile. In this framework, we use the method from Jaffe and Gelfenbuam [2007] to calculate the suspended sediment concentration profile. It is efficient to 
reconstruct the deposit by calculating times of deposition. The deposition time of suspended sediment is calculated by:

$$
t_{j}^{(i)}=\frac{z_{j}}{w_{s}^{(i)}}
$$

in which $t_{j}^{(i)}$ is the deposition time for grain size $i$ sediment at elevation $z_{j}$. The amount of sediment settling in each grain size class for a given elevation is tracked by

$$
\zeta_{j}^{(i)}=\frac{C_{j}^{(i)}}{1-p}
$$

in which $C_{j}^{(i)}$ is the suspended sediment profile [Jaffe and Gelfenbuam 2007]. $\zeta_{j}^{(i)}$ is the sediment thickness increment of the same grain size $i$ at elevation $z_{j}$ and deposited at time $t_{j}^{(i)}$. The deposition time and corresponding sediment thickness increment are ordered from shortest to longest. If there are multiple layers in the tsunami sediment, we can compute the grain-size distribution for each layer separately based on the depositional temporal order of the sediment thickness increments by:

$$
f_{k}^{(i)}=\frac{\sum_{j=0}^{M} \zeta_{j}^{(i)}}{\sum_{i=0}^{N}\left(\sum_{j=0}^{M} \zeta_{j}^{(i)}\right)} ; i=1,2,3, \ldots, N ; j=1,2,3, \ldots, M
$$

where $f_{k}^{(i)}$ is the sediment fraction of grain size $i$ in layer $k . \sum_{j=0}^{M} \zeta_{j}^{(i)}$ is total sediment thickness with the same grain size $i$ in sediment layer $k$. Index $j$ is used to mark the original location of sediment in the water column. $\sum_{i=0}^{N}\left(\sum_{j=0}^{M} \zeta_{j}^{(i)}\right)$ is the total thickness of this sediment layer which contains all grain size classes. In TSUFLIND, the calculation of tsunami flow condition will use the same method as TsuSedMod model [Jaffe and Gelfenbuam 2007]. 


\subsection{Result Evaluation}

We employ the second norm to quantify the error between model and observed results as a control of the iterative procedure. The second norm of error for layer $k$ is given by:

$$
L_{k}=\sqrt{\frac{\sum_{i=1}^{N}\left(f_{m}^{(i)}-f_{o}^{(i)}\right)^{2}}{N}}
$$

$f_{m}^{(i)}$ and $f_{o}^{(i)}$ are the modeled and observed percentage for each grain size class $i$. With the help of $L_{k}$, we compute the average second norm value for a location with:

$$
\bar{L}=\frac{1}{K} \sum_{k=1}^{K} L_{k}
$$

We define $\bar{L} \leq 5 \%$ as a good simulation. For the tsunami sediment thickness simulation, we employ the same process. The second norm value of error for thickness between the model result and the field observation is given by:

$$
L_{t h}=\sqrt{\frac{\sum_{j=1}^{Q}\left(\frac{t h_{m}-t h_{f}}{t h_{f}} \cdot 100 \%\right)^{2}}{Q}}
$$

where $t h_{m}$ and $t h_{f}$ are the modeled and observed thicknesses for each sample location, $Q$ is the number of sample locations. As there is only a limited number of tsunami deposit samples for the test case applied here, we use $10 \%$ as the threshold value.

\subsection{Offshore Wave Characteristics and Flooding}

In order to estimate a representative offshore tsunami amplitude, we relate the water volume calculated from Sousby's model at maximum inun- 
dation with the volume calculated by numerically solving the shallow water equation. We carry out a parameter study by varying the slope $(m)$ and the offshore wave amplitude $(\xi)$. For more details about the parameter study and employed numerical model, we refer to Appendix B. The water depth computed from Soulsby's model is used to calculate the volume of the inundation water. With the help of numerical simulations (Appendix B), we derived the following formulation:

$$
\begin{aligned}
\xi= & \lambda_{1}+\lambda_{2} \cdot V+\lambda_{3} \cdot m+\lambda_{4} \cdot V^{2}+\lambda_{5} \cdot m \cdot V+\lambda_{6} \cdot m^{2} \\
& +\lambda_{7} \cdot V^{3}+\lambda_{8} \cdot V^{2} \cdot m+\lambda_{9} \cdot V \cdot m^{2}+\lambda_{10} \cdot m^{3}
\end{aligned}
$$

Where $\xi$ is offshore wave height, $V$ is the water volume that covers the land at maximum inundation, $m$ is the slope of beach profile. These constants $\lambda$ in Eq 16 are $\lambda_{1}=5.06, \lambda_{2}=2.93, \lambda_{3}=-0.28, \lambda_{4}=0.51, \lambda_{5}=-3.04$, $\lambda_{6}=0.0014, \lambda_{7}=0.027, \lambda_{8}=-0.011, \lambda_{9}=0.051, \lambda_{10}=0.053$.

\subsection{Inversion Framework and Coupling}

We use the information from all three models as different components in this joint inversion framework. The steady flow condition that is presented in all models, is also presented in TSUFLIND and represents the most simplifying assumption. The inputs to TSUFLIND are the sediment characteristics for different sampling locations along a slope. However, it should be noted that the inversion of the flow conditions is carried out for each sample location individually. TSUFLIND uses components from Moore model, Soulsby's model and TsuSedMod model to adjust the sediment source grain-size distribution, the sediment source concentration and the average flow velocity 
to simulate tsunami sediment thickness and grain-size distribution along the slope in the deposition zone. If needed, the representative offshore wave amplitude can be computed. Figure 2 depicts the flowchart outlining how the joint inversion model works.

\section{[Figure 2 about here.]}

The information needed for a successful inversion includes the grain-size distribution, sediment thickness as well as the information of the slope along which the tsunami sediments were sampled. It should be noted that TSUFLIND can handle volume and weight based grain-size distributions that are generated with various of methods. However, in general, settling tube measurements are preferred. In the inversion framework, Moore's advection model is employed to calculate the initial flow speed. Because Moore's model uses the actual data from measured sediment distributions, it reduces the number of iterations, significantly. The reservoir of sediments in the water column is calculated by following Madsen et al. [1993], and it is assumed that all grain-size distributions can be described with log-normal distributions. The iteration begins by computing the inundation $\left(R_{w}\right.$ in Fig. 1$)$ with the help of Soulsby's model, and the initial estimate of the flow condition is from Moore's advection model. The result of this step is the local flow depth and the entire sediment thickness at each sample location. Our sediment formation module calculates the characteristics of the deposited sediments. The number of iterations is controlled by the error norm between the simulated and observed deposits and stop after the predefined threshold is met. The model outputs are flow speed and depth, the Froude number and a range of offshore reference wave amplitudes. 


\section{Application and Example}

\subsection{Field Observation and Data}

We employ the field data [Bahlburg and Weiss 2007] from the 2004 Indian Ocean tsunami to demonstrate the capabilities of our framework (Fig. 3). These samples come from the coastal area in the vicinity of Ranganathapuram, India. Bahlburg and Weiss [2007] identify sediment layers formed by the tsunami in this cross section and described grain-size distributions for each layer. There are some grass runners on the top of the tsunami sediment, which indicate the return flow direction and the erosion caused by the return flow. Most grain-size distributions of the sediment layers in the test case are unimodal (Fig. 3b). Tsunami deposits in this cross section are usually well sorted, and the mean grain size is between 0.5 and 1.5 in $\phi$ scale, which corresponds to medium and coarse sand. Furthermore, Bahlburg and Weiss [2007] observe that the mean grain size is upward and landward fining in this cross section. For the inversion of flow depth, speed, Froude number and offshore wave amplitude in the TSUFLIND, the deposit thickness and grain-size distribution along all section are needed as inputs. Flow depth in this model will take full use of both the field observations and the model results from Soulsby's model.

\subsection{Sedimentary Simulation Results}

TSUFLIND first simulates tsunami deposit thickness (Fig. 3c). In the test case, the largest observed thickness is about 0.22 meters at 120 meters inland. For the first 100 meters in this cross section, the simulated thickness from TSUFLIND is larger than the field measurement. After 200 meters 
inland, the simulated thicknesses decrease quickly and generally fit with the field measurement.

TSUFLIND reconstructs sediment grain-size distributions for both the entire tsunami deposit and several vertical intervals at any given sample locations. The error of the entire tsunami sediment grain-size distribution in this test case is from $0.38 \%$ to $1.54 \%$, which can be considered good simulation results. The error is less than $1.0 \%$ from 120 meters to 160 meters inland and then increases to $1.5 \%$ after 160 meters inland. We use four sediment samples to calculate grain-size distributions (Fig. 3d $I-I V$, response to $120 \mathrm{~m}, 160 \mathrm{~m}, 177 \mathrm{~m}$ and $207 \mathrm{~m}$ from shoreline). Beyond 160 meters inland, there are fewer coarse grains and more fine grains in the simulated grain-size distribution than the field measurement (Fig. 3d, I, III and $I V$ ).

[Figure 3 about here.]

In order to study how the grain-size distribution changes in the vertical direction, we employ the new sediment formation module (See Section 2.2) to simulate tsunami deposit grading. Figure 3a shows grain-size distribution for several vertical intervals at four different study locations. The grain size for these reconstruction results ranges from 0 to 6 in $\phi$ scale. The number of vertical intervals decreases toward the inland extent of the deposits. The simulated deposits exhibit features such as the well-known fining inland and fining upward.

Based on the grain-size distribution for each vertical interval (Fig. 3a), mean grain size, kurtosis, skewness and sorting factor can be calculated for locations that are at least $110 \mathrm{~m}$ away from the shoreline. The mean grain size 
in the bottom portion of the deposit does not significantly change (around $1.2 \phi)$. However, the mean grain size decreases toward the top of the deposit about $2.2 \phi$. The change in kurtosis is about 0.8 to 1.1 in this sample. Sediment simulation results in this example also show that tsunami sediment changes from moderate sorted at the bottom to well sorted at the top. The grain-size distribution is positively skewed.

\subsection{Hydrodynamic Inversion Results}

After reconstructing the grain-size distributions, TSUFLIND calculates the flow speed and Froude number at the sample locations. For the test case, Fig.4a and 4b show the flow speed and Froude number distribution along the slope. The average flow speed decreases from $4.7 \mathrm{~ms}^{-1}$ at 150 meter inland to $3.3 \mathrm{~ms}^{-1}$ at 350 meter inland. The Froude number, which is around 0.9 , does not change significantly along the slope. Furthermore, the range of possible velocities and Froude numbers decreases from 150 meters to 350 meters inland.

The flow speed profile is influenced by the eddy viscosity profile and shear velocity. The eddy viscosity profile parametrizes the vertical distribution of turbulent stress. TSUFLIND follows the flow eddy viscosity profile based on laboratory data from Gelfenbaum and Smith [1986]. While the flow speed has the largest value on the water surface and decreases toward the sediment bed, TSUFLIND only calculates the depth-averaged velocities as final results.

[Figure 4 about here.]

TSUFLIND computes the water surface profile to estimate the water volume when the tsunami wave reaches the maximum inundation. With the 
help of Eq (16), the wave amplitude can be estimated based on the slope $(m)$ and the water volume $(V)$. For the Eastern India case, the wave amplitudes range from 5 to 7 meters and the wavelength is close to $50 \mathrm{~km}$.

\section{Discussion}

\subsection{Interpretation of test case results}

With the help of the presented model, we can reproduce tsunami sediments as well as infer the flow condition based on observations and laboratory measurements of existing tsunami deposits. Figure 3 summarizes the results of our simulation for the tsunami deposits. The apparent difference of the deposit thickness between model results and observations for distances smaller than 120 meters from the shoreline can be explained by strong return flow or large velocities from subsequent waves with small inundation. For distances from the coastline larger than 120 meters, the deposit simulated thicknesses match well with the observations. However, the observations are slightly larger due to the presence of topographic change that may slow down the flow (Fig 3c and d). The finer grain sizes contain the largest error between observation and model result. It is likely that the topographic changes are the main source of the error. However, the difference could also be a part of the model uncertainty.

The calculated mean speed decreases from $4.7 \mathrm{~ms}^{-1}$ to $3.3 \mathrm{~ms}^{-1}$ along the studied section. The speed decreases continuously shown as Fig 4a, the Froude number increases and then decreases (Fig. 4b). The mean Froude number is around 0.9 for this test case. As the flow depth decreases toward the maximum inundation with a constant slope, the calculated decrease in 
the Froude number can only be explained by a decrease in the velocity. At first, the flow speed decreases less slowly than the water depth, so the mean Froude number increases in this area (150 meters to 300 meters). After 300 meters, the flow decelerates quickly and causes the Froude number to decrease. The flow speed and Froude number results from TSUFLIND are shown as ranges of possible values with uncertainties (Fig. 4a and 4b). The ranges of the speed and the Froude number decrease from $150 \mathrm{~m}$ to $350 \mathrm{~m}$, which indicates the uncertainties decrease towards the sample location close to the landward sediment pinch-out. It is possible that the tsunami deposits near the maximum run-up position become thin, well-sorted and fine-grained containing less information about the flow condition. Tsunami wave amplitudes calculated by TSUFLIND are usually larger than real amplitudes, because the mathematical relationship (Eq. 16) is based on frictionless shallow water equations.

\subsection{Model limitation and improvement}

In this study, we combine three tsunami inversion models to simulate tsunami deposit and estimate tsunami flow parameters. All three models are based on model-specified basic assumptions. A significant assumption of TSUFLIND is that the sediment transport and the deposition process during a tsunami are considered uniform in space and time. Consequently, the deposit comes from both horizontal convergence and suspension settling. TSUFLIND combines Sousby's model and TsuSedMod to simulate these two processes. This combination greatly improves the grain-size distribution simulation results. However, when the tsunami flow decelerates rapidly because of bathymetic or topographic changes or any other reasons, some part of the 
deposit would be eroded again. If the flow is strong enough, a significant part of tsunami deposit may be eroded, just like the result shown in Fig. 3c from shoreline to 100 meters in land. As a result, the tsunami speed calculated by TSUFLIND represents an underestimation.

Another significant assumption of TSUFLIND is that most of tsunami deposits is transported by the suspension load and ignores the contribution of bed load. This assumption results into an overestimation of the tsunami flow speed and increase the percentage of coarse fraction in the grain-size distribution. TSUFLIND is not applicable for a case in which bed load is the dominant sediment transport mode. In order to reduce the effect of bed load, only the suspension-grading fraction of the measured grain size distribution should be considered as input for inversion with TSUFLIND. However, it should be noted that suspension-grading is not easy to identify in grain-size distribution. TSUFLIND is designed to handle unimodal grain-size distribution. However, polymodal grain-size distributions can be deconvoluted, and TSUFLIND can be employed to invert tsunami flow characteristics for the different deconvoluted grain-size distributions, individually.

TSUFLIND has three aspects that require improvement: the applicable flow condition, the accuracy of final outputs including sediment simulation and flow speed calculation and capabilities to deal with post-depositional processes. The improvement of the applicable area can be made by employing other tsunami propagation models instead of Sousby's model, which can deal with non-uniform and unsteady flows. At the same time, the new model needs to consider both the suspension load and bed load. Also a new method for combining forward and inverse modeling will hold great promise 
for deciphering quantitative information from tsunami deposits and decreasing the uncertainties in tsunami sediment transport simulation and inversion results [Sugawara et al. 2014]. Furthermore, post-depositional processes may alter the grain-size distribution and the thickness of tsunami deposit as documented by Szczuciński et al. [2007], Szczuciński [2012], Spiske et al. [2013a] and Bahlburg and Spiske [2015]. More quantitative data on how the postdepositional processes affect tsunami deposits are needed to derive empirical formulae to consider such changes in inversion model.

\section{Conclusion}

Modeling the tsunami sediment deposition processes and estimating tsunami flow parameters will greatly improve not only the understanding of deposition from tsunami but also the hazard assessment for extreme high-energy events. The combination of different inversion models allows the computation of a wide range of tsunami wave impacts or characteristics, ranging from sediment thickness, grain size distribution to flow speed and wave amplitude. Based on comparisons between our model results and field observation from post-tsunami surveys of the 2004-Sumatra (India), TSUFLIND appears to simulate tsunami deposit thickness and grain-size distribution with small error. Furthermore, our results show that TSUFLIND gives reasonable approximations of tsunami flow parameters like flow speed and Froude number for the 2004 Indian ocean tsunami case. However, these results are restricted by the flow condition. If there were strong return flows or subsequent waves, the results from TSUFLIND will contain some uncertainties. From a general point of view, with a simple bathymetry, the tsunami and paleotsunami 
as well as other extreme events can be understood with the help of TSUFLIND. More research needs to be done to improve TSUFLIND to quantify and reduce the uncertainties in the inversion results and expand applicable conditions.

\section{Acknowledgement}

We would like to thank Dr. Spiske (University of Trier) for her constructive review. The work presented in here is based upon work partially supported by the National Science Foundation under grants NSF-CMMI1208147 and NSF-CMMI-1206271.

\section{Appendix A}

Table 1: Symbols List

\begin{tabular}{lll}
\hline Symbol & Unit & Description \\
\hline$h$ & $\mathrm{~m}$ & Water depth \\
$w_{s}$ & $\mathrm{~ms}^{-1}$ & Settling velocity of the sediment grain \\
$l$ & $\mathrm{~m}$ & Horizontal distance a grain travels to be deposited \\
$\gamma$ & - & Run-up time constant \\
$T$ & $\mathrm{~s}$ & Inundation time \\
$H$ & $\mathrm{~m}$ & Maximum flow depth at a given location during tsunami inundation \\
$\Delta h$ & $\mathrm{~m}$ & Water depth increment due to tsunami \\
$m$ & - & Slope \\
$R_{z}$ & $\mathrm{~m}$ & Vertical water inundation limit \\
$H_{0}$ & $\mathrm{~m}$ & Maximum water depth at the shoreline \\
$\zeta_{0}^{(i)}$ & $\mathrm{m}$ & Thickness of the deposit for grain size $i$ at the shoreline \\
$T_{d}$ & $\mathrm{~s}$ & Deposition time
\end{tabular}


Table 1 Continued: Symbols List

\begin{tabular}{|c|c|c|}
\hline$C_{0}^{(i)}$ & $\mathrm{m}^{3} / \mathrm{m}^{3}$ & Depth averaged sediment concentration for grain size $i$ \\
\hline$p$ & - & Porosity \\
\hline$\zeta^{(i)}$ & $\mathrm{m}$ & Sediment thickness for grain size $i$ \\
\hline$R_{s}^{(i)}$ & $\mathrm{m}$ & Distance between sediment extend and the shoreline for grain size $i$ \\
\hline$\Delta \eta^{(i)}$ & $\mathrm{m}$ & Sediment thickness increment for grain size $i$ \\
\hline$C^{(i)}(z)$ & $\mathrm{m}^{3} / \mathrm{m}^{3}$ & Sediment concentration profile for grain size $i$ \\
\hline$z_{o}$ & $\mathrm{~m}$ & Bottom roughness \\
\hline$K(z)$ & $\mathrm{kgm}^{-1} \mathrm{~s}^{-1}$ & Eddy viscosity profile \\
\hline$C_{r}^{(i)}$ & $\mathrm{m}^{3} / \mathrm{m}^{3}$ & Reference sediment concentration \\
\hline$\beta_{0}$ & - & Resuspension coefficient \\
\hline$f^{(i)}$ & $\%$ & Percentage of the sediment of grain size $i$ \\
\hline$S^{(i)}$ & - & Normalized excess shear stress \\
\hline$\tau_{b}$ & $\mathrm{kgm}^{-1} \mathrm{~s}^{-2}$ & Bed shear stress \\
\hline$\tau_{c r}^{(i)}$ & $\mathrm{kgm}^{-1} \mathrm{~s}^{-2}$ & Critical shear stress of the initial sediment movement for grain size $i$ \\
\hline$N$ & - & Number of grain size classes \\
\hline$z_{j}$ & $\mathrm{~m}$ & Sediment original elevation \\
\hline$t_{j}^{(i)}$ & $\mathrm{s}$ & Deposition time for grain size $i$ sediment at elevation $z_{j}$ \\
\hline$L_{k}$ & - & Second norm of error for layer $k$ 's grain-size distribution \\
\hline$f_{m}^{(i)}$ & $\%$ & Modeled percentages for grain size class $i$ \\
\hline$f_{o}^{(i)}$ & $\%$ & Observed percentages for grain size class $i$ \\
\hline $\bar{L}$ & - & Average second norm value of grain-size distribution for a location \\
\hline$L_{t h}$ & - & Second Norm value of thickness between the model result and the field observation \\
\hline$t h_{m}$ & $\mathrm{~m}$ & Modeled thicknesses \\
\hline$t h_{f}$ & $\mathrm{~m}$ & Observed thicknesses \\
\hline$Q$ & - & Number of sample locations \\
\hline$\xi$ & $\mathrm{m}$ & Offshore wave amplitude \\
\hline$V$ & $\mathrm{~m}^{3}$ & Water volume that covers the land at maximum inundation \\
\hline$R_{w}$ & $\mathrm{~m}$ & Distance of water run-up to shoreline (Inundation) \\
\hline$\eta(x, t)$ & $\mathrm{m}$ & Solitary wave form \\
\hline
\end{tabular}


Table 1 Continued: Symbols List

$\begin{array}{lll}C & \mathrm{~ms}^{-1} & \text { Wave celerity } \\ u(x, t) & \mathrm{ms}^{-1} & \text { Horizontal velocity in shallow water equations } \\ g & \mathrm{~ms}^{-2} & \text { Gravitational constant } \\ B(x) & \mathrm{m} & \text { Bed topography function } \\ d & \mathrm{~m} & \text { Water depth of continental shelf }\end{array}$

where

$$
k=\sqrt{\frac{3 \xi}{4 d^{3}}}
$$

$388 \xi$ is the wave amplitude and $d$ is the water depth of continental shelf, which 389 is assumed as 500 meters. $C$ is the wave celerity which is expressed as: 


$$
C=\sqrt{g(h+H)}
$$

Initial velocity in shallow water equation code is set as:

$$
v_{0}(x, t)=\sqrt{g / h_{0}} \eta_{(x, t=0)}
$$

We calculate the water volume when tsunami wave got the maximum runup based on water distribution function $h(x)$. Water depth function $h(x)$ comes from a shallow water equations code. The shallow water equations code used here originally is designed for studying the propagation and runup of solitary wave by using a high-resolution finite volume method to solve following equations[Delis et al. 2008]:

$$
\begin{gathered}
\frac{\partial h}{\partial t}+\frac{\partial(u h)}{\partial x}=0 \\
\frac{\partial(u h)}{\partial t}+\frac{\partial}{\partial x}\left(h u^{2}+\frac{1}{2} g h^{2}\right)=-g h \frac{d B}{d x}
\end{gathered}
$$

where $h(x, t)$ is the flow depth, $u(x, t)$ is the horizontal velocity, $g$ is the gravitational constant, $B(x)$ is the bed topography function.

In this code, a conservative form of the nonlinear shallow water equations with source term is solved by using a high-resolution Godunov-type explicit scheme with Roe's approximate Riemamn solver [Delis et al. 2008]. In order to get the mathematical relationship between the maximum water volume $(V)$, slope $(m)$ and initial wave amplitude $(\xi)$, we design a parameter study by varying slope and wave amplitude to calculate the water volume. Finally, we use curve fitting methods to get the mathematical relationship based on parameter study data set. 
Bahlburg, H. and Spiske, M. (2015). Styles of early diagenesis and the preservation potential of onshore tsunami deposits - a re-survey of isla mocha, central chile, 2 years after the february 27, 2010, maule tsunami. Sedimentary Geology, 326:33 - 44 .

Bahlburg, H. and Weiss, R. (2007). Sedimentology of the december 26, 2004, sumatra tsunami deposits in eastern india (tamil nadu) and kenya. International Journal of Earth Sciences, 96(6).

Benner, R., Browne, T., Brückner, H., Kelletat, D., and Scheffers, A. (2010). Boulder transport by waves: Progress in physical modelling. Zeitschrift für Geomorphologie, Supplementbände, 54(3):127-146.

Bourgeois, J., Hansen, T. A., Wiberg, P. L., and Kauffman, E. G. (1988). A tsunami deposit at the cretaceous-tertiary boundary in texas. Science, 241(4865):pp. 567-570.

Delis, A. I., Kazolea, M., and Kampanis, N. A. (2008). A robust highresolution finite volume scheme for the simulation of long waves over complex domains. International Journal for Numerical Methods in Fluids, $56(4): 419-452$.

Gelfenbaum, G. and Smith, J. D. (1986). Experimental evaluation of a generalized suspended-sediment transport theory.

Hutchinson, I., Clague, J. J., and Mathewes, R. W. (1997). Reconstructing the tsunami record on an emerging coast: A case study of kanim lake, vancouver island, british columbia, canada. Journal of Coastal Research, $13(2):$ pp. 545-553. 
Jaffe, B., Buckley, M., Richmond, B., Strotz, L., Etienne, S., Clark, K., Watt, S., Gelfenbaum, G., and Goff, J. (2011). Flow speed estimated by inverse modeling of sandy sediment deposited by the 29 september 2009 tsunami near satitoa, east upolu, samoa. Earth-Science Reviews, 107(1-2):23 - 37. The 2009 South Pacific tsunami.

Jaffe, B. E. and Gelfenbuam, G. (2007). A simple model for calculating tsunami flow speed from tsunami deposits. Sedimentary Geology, 200(3-4):347 - 361. Sedimentary Features of Tsunami Deposits - Their Origin, Recognition and Discrimination: An Introduction.

Jaffe, B. E., Goto, K., Sugawara, D., Richmond, B. M., Fujino, S., and Nishimura, Y. (2012). Flow speed estimated by inverse modeling of sandy tsunami deposits: results from the 11 march 2011 tsunami on the coastal plain near the sendai airport, honshu, japan. Sedimentary Geology, 282(0):90 - 109. The 2011 Tohoku-oki tsunami.

MacWilliams, M. L. (2004). Three-dimensional hydrodynamic simulation of river channels and floodplains. $\mathrm{PhD}$ thesis, Stanford University.

Madsen, O., Wright, L., Boon, J., and Chisholm, T. (1993). Wind stress, bed roughness and sediment suspension on the inner shelf during an extreme storm event. Continental Shelf Research, 13(11):1303 - 1324.

Martin, M. E., Weiss, R., Bourgeois, J., Pinegina, T. K., Houston, H., and Titov, V. V. (2008). Combining constraints from tsunami modeling and sedimentology to untangle the 1969 ozernoi and 1971 kamchatskii tsunamis. Geophysical Research Letters, 35(1):n/a-n/a. 
Moore, A. L., McAdoo, B. G., and Ruffman, A. (2007). Landward fining from multiple sources in a sand sheet deposited by the 1929 grand banks tsunami, newfoundland. Sedimentary Geology, 200(3-4):336 - 346. Sedimentary Features of Tsunami Deposits - Their Origin, Recognition and Discrimination: An Introduction.

Nandasena, N. and Tanaka, N. (2013). Boulder transport by high energy: Numerical model-fitting experimental observations. Ocean Engineering, $57(0): 163-179$.

Noormets, R., Crook, K. A., and Felton, E. A. (2004). Sedimentology of rocky shorelines: 3.: Hydrodynamics of megaclast emplacement and transport on a shore platform, oahu, hawaii. Sedimentary Geology, 172(1-2):41 - 65 .

Nott, J. (1997). Extremely high-energy wave deposits inside the great barrier reef, australia: determining the cause - tsunami or tropical cyclone. Marine Geology, 141(1-4):193 - 207.

Smith, D., Foster, I., Long, D., and Shi, S. (2007). Reconstructing the pattern and depth of flow onshore in a palaeotsunami from associated deposits. Sedimentary Geology, 200(3-4):362 - 371. Sedimentary Features of Tsunami Deposits - Their Origin, Recognition and Discrimination: An Introduction.

Soulsby, R., Smith, D., and Ruffman, A. (2007). Reconstructing Tsunami Run-Up from Sedimentary Characteristics: A Simple Mathematical Model, chapter 83, pages 1075-1088. 
Spiske, M., Piepenbreier, J., Benavente, C., and Bahlburg, H. (2013a). Preservation potential of tsunami deposits on arid siliciclastic coasts. Earth-Science Reviews, 126:58 - 73.

Spiske, M., Piepenbreier, J., Benavente, C., Kunz, A., Bahlburg, H., and Steffahn, J. (2013b). Historical tsunami deposits in peru: Sedimentology, inverse modeling and optically stimulated luminescence dating. Quaternary International, 305(0):31 - 44. Ranked habitats and the process of human colonization of South America.

Spiske, M., Weiss, R., Bahlburg, H., Roskosch, J., and Amijaya, H. (2010). The tsusedmod inversion model applied to the deposits of the 2004 sumatra and 2006 java tsunami and implications for estimating flow parameters of palaeo-tsunami. Sedimentary Geology, 224(1-4):29 - 37.

Sugawara, D., Goto, K., and Jaffe, B. E. (2014). Numerical models of tsunami sediment transport - current understanding and future directions. Marine Geology, 352(0):295 - 320. 50th Anniversary Special Issue.

Szczuciński, W. (2012). The post-depositional changes of the onshore 2004 tsunami deposits on the andaman sea coast of thailand. Natural Hazards, $60(1): 115-133$.

Szczuciński, W., Niedzielski, P., Kozak, L., Frankowski, M., Zioła, A., and Lorenc, S. (2007). Effects of rainy season on mobilization of contaminants from tsunami deposits left in a coastal zone of thailand by the 26 december 2004 tsunami. Environmental Geology, 53(2):253-264. 
497 Tang, H. and Weiss, R. (2014). Tsuspeedv0.5: Inversion of flow depth and 498 flow speed along a cross section. In 2014 AGU Fall Meeting.

499 Witter, R., Jaffe, B., Zhang, Y., and Priest, G. (2012). Reconstructing hy500 drodynamic flow parameters of the 1700 tsunami at cannon beach, oregon, 501 usa. Natural Hazards, 63(1):223-240. 


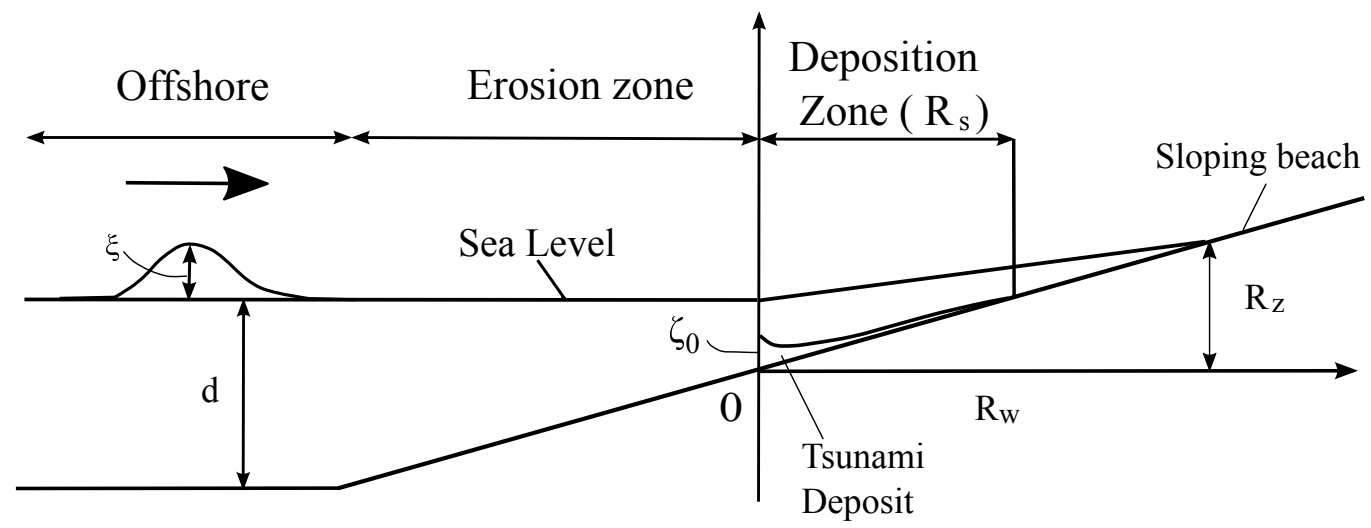

Figure 1: Conceptual model of TSUFLIND with definition of the terminology used later in the paper. For more symbols used in this paper see Appendix A. 


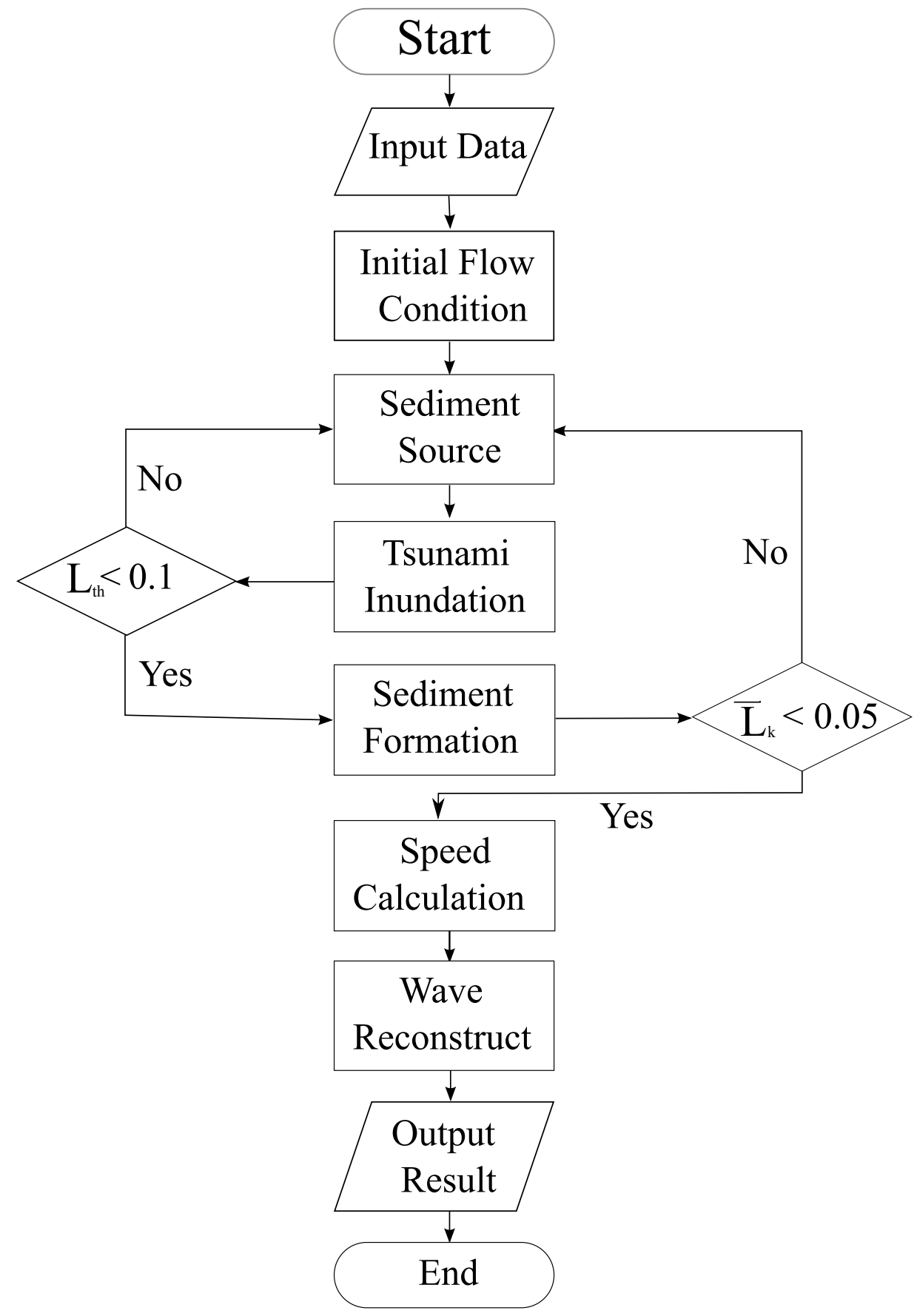

Figure 2: Flowchart for TSUFLIND's iterative scheme to simulate tsunami deposit and estimate tsunami flow condition. 
(a)

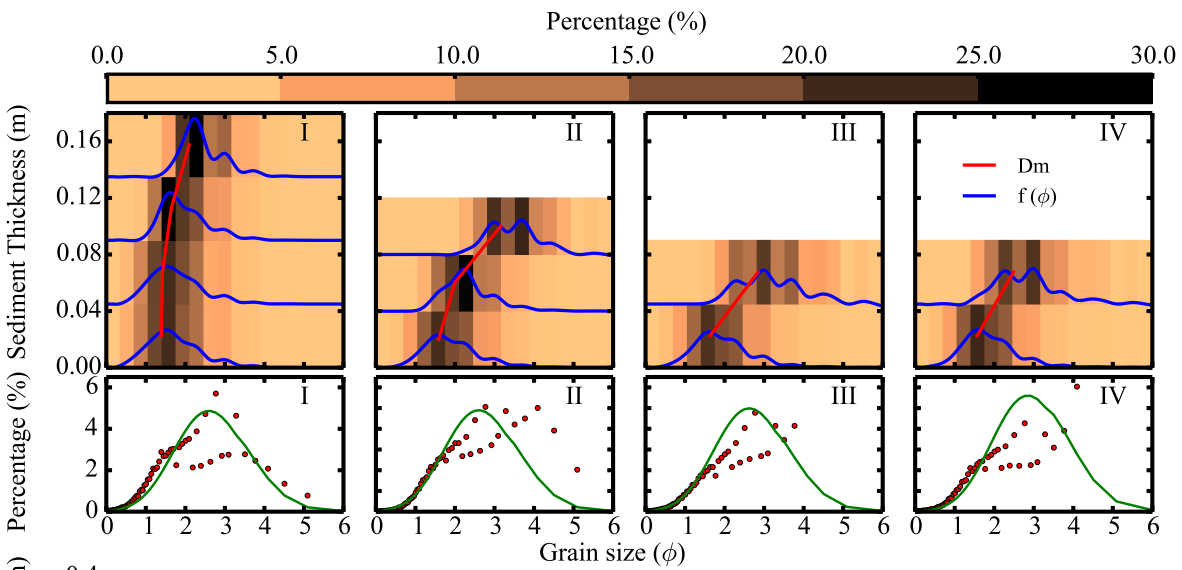

(c)

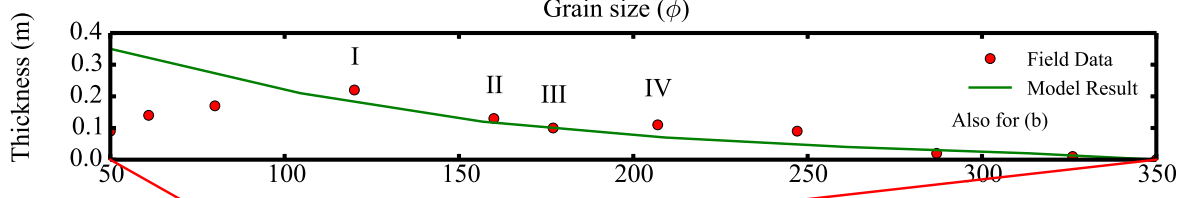

(d)

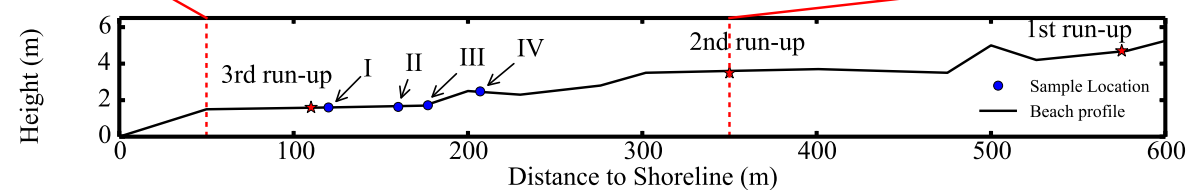

Figure 3: TSUFLIND simulation results and field measurement at Ranganathapuram, India. a: Vertical grading in grain size distribution (blue line) and mean grain size (red line) for four sampled locations (120m, 160m, 177m and 207m); b: the entire tsunami deposit grain-size distributions used as inputs to TSUFLIND (red points) and model result outputs from TSUFLIND (green line); c: tsunami deposit thickness field measurements (red points) and simulation results from TSUFLIND (green line); d: topography, wave run up and sample locations for test case (I : 120m; II : 160m; III: 177m; IV : 207m). 
(a)

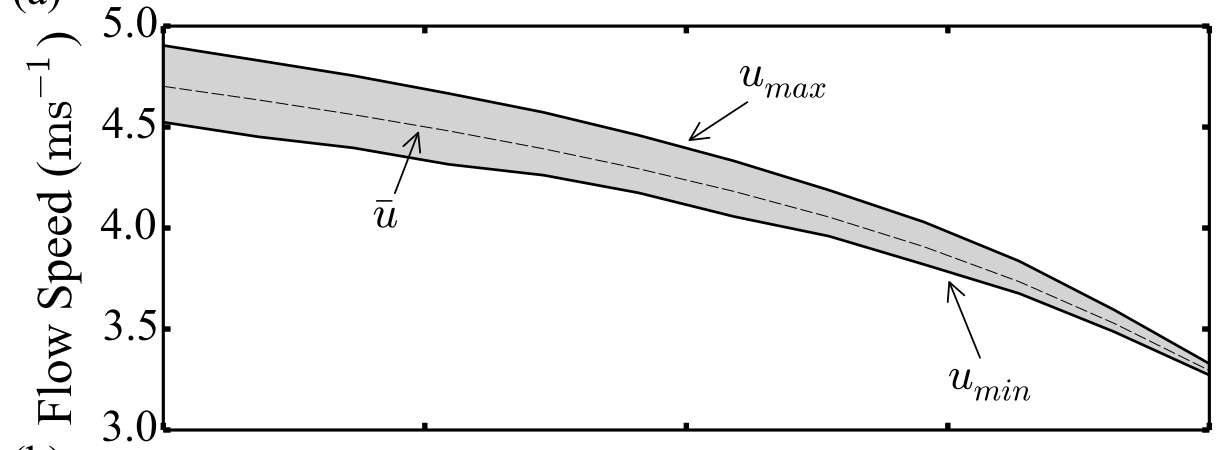

(b)

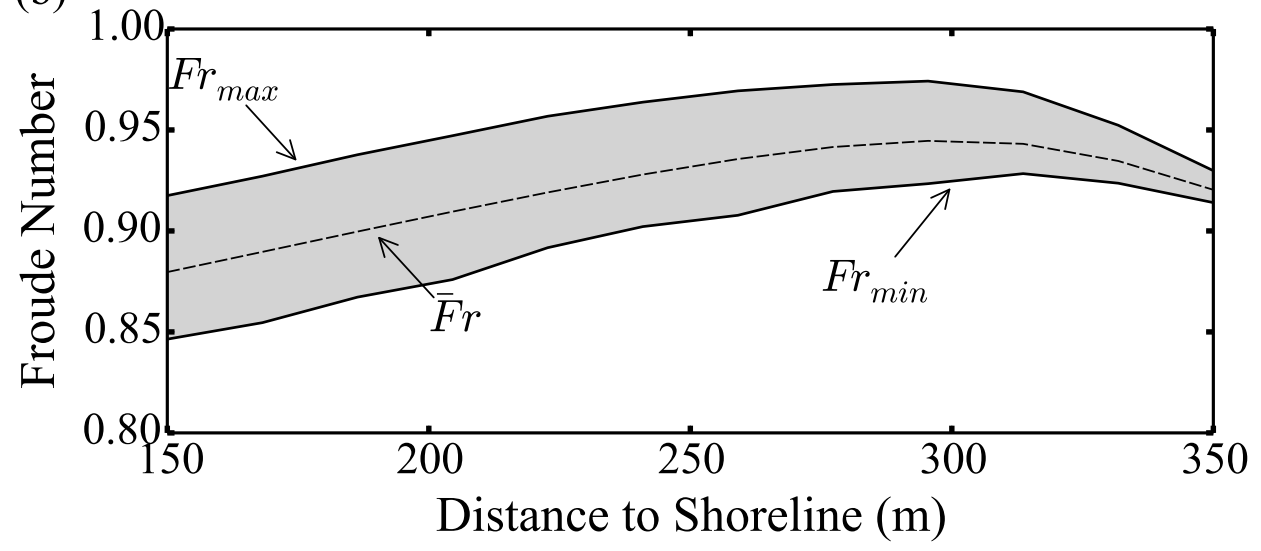

Figure 4: The estimated flow speeds and Froude numbers from TSUFLIND. a: Tsunami flow speed estimates are indicated by the gray area with the boundaries of maximum and minimum possible speeds. The dashed line is the average value of estimated flow speeds. b: Froude number estimates are indicated by the gray area in this figure with the maximum and minimum possible values. The dashed line is the average value of Froude number. 